Filol. linguíst. port., n. 14(1), p. 99-120, 2012.

\title{
Carta-resposta ao Governador Capitáo-general Luiz de Albuquerque de Mello Pereira e Cáceres: estudo filológico
}

\author{
Camila Lemos de Almeida ${ }^{1}$ \\ Elias Alves de Andrade ${ }^{2}$
}

\begin{abstract}
Resumo: Este artigo tem por objetivo o estudo filológico de um manuscrito datado de 15 de janeiro de 1784, escrito no Rio de Janeiro, pertencente ao acervo do Arquivo Público de Mato Grosso, do qual serão feitas as edições fac-similar e semidiplomática, a análise de aspectos paleográficos e a abordagem de características relativas às funções adjetiva e transcendente da Filologia, conforme definidas em Spina (1977: 77). Esta atividade está vinculada aos projetos: "Para a História do Português Brasileiro - PHPB" - e "Estudo do português em manuscritos produzidos em Mato Grosso a partir do século XVIII”, do Programa de Pós-Graduação em Estudos de Linguagem - MeEL - do Instituto de Linguagens da Universidade Federal de Mato Grosso.
\end{abstract}

Palavras-chave: Edição; Filologia; Funções Adjetiva e Transcendente; Manuscrito; Paleografia.

\section{INTRODUÇÃO}

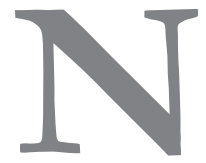

este artigo tem-se por objetivo o estudo, sob a ótica da Filologia, de um manuscrito datado de 15 de janeiro de 1784, produzido no Rio de Janeiro, pertencente ao acervo do Arquivo Público de Mato Grosso - APMT, do qual serão feitas as edições fac-similar e semidiplomática, entendida a primeira como a reprodução mecânica do testemunho, e a segunda, uma transcrição dele, em que apenas se transforma o texto manuscrito em tipografado, além do desdobramento das abreviaturas, visando à facilidade de leitura (Spina: 1977, p. 77). Serão também analisadas características paleográficas, assim como abordados aspectos das funções

1 Universidade Federal de Mato Grosso (MeEL/IL/UFMT). E-mail: camila.lemos@ymail. com.

2 Universidade Federal de Mato Grosso (MeEL/IL/UFMT). E-mail: elias@ufmt.br. 
adjetiva da Filologia, através da qual se analisam questões atinentes à autoria, dentre outras, e transcendente, pela qual se abstrai do texto para observar estudar o que dele se depreende quanto a características da vida, dos costumes e das circunstâncias históricas em que o texto foi escrito.

A escrita surgiu quando o homem, no período neolítico, tornou-se menos nômade, menos errante e começou a formar aldeias, a cultivar seu alimento e a domesticar animais, o que o levou, instigado pela necessidade, a criar recursos para registrar o número de animais que possuía e quanto alimento havia estocado (Lobo, 1968: 35 e Pirenne, 1973: 13). Mais tarde, já dispondo da escrita, passou a registrar seus hábitos e costumes, batalhas, tratados, produção literária, atos públicos de governantes, acontecimentos sociais, convicções religiosas etc. Em suma, a escrita propiciou à humanidade a possibilidade de registrar sua história, permitindo a guarda e a propagação de informações entre indivíduos e gerações.

Higounet (2003:10) refere-se à relação entre homem-escrita-história:

A escrita faz de tal modo parte da nossa civilização que poderia servir de definição própria. A história da humanidade se divide em duas imensas eras: antes e a partir da escrita [...]. Vivemos os séculos da civilização da escrita. Todas as nossas sociedades baseiam-se sobre o escrito. A lei escrita substitui a lei oral, o contrato substituiu a convenção verbal, a religião escrita se seguiu à tradição lendária. E, sobretudo, não existe história que não se funde sobre textos.

O texto, escrito ou impresso, antigo ou moderno, constitui o objeto de estudo da Filologia. Seu início se dá na biblioteca de Alexandria, maior centro de cultura helênica da Antiguidade, no período helenístico ou alexandrino da civilização grega, ciência que prima pela valorização do passado, pela ordenação e catalogação de obras, com destaque para os poemas épicos de Homero.

Segundo Spina (1977:61),

Foi, portanto, do amor à poesia que nasceu a ciência filológica. Voltados para a restauração, intelecção e explicação dos textos, o labor desses eruditos consistiu em catalogar as obras, revê-las, emendá-las, comentá-las, provê-las de sumários e de apostilas ou anotações (escólios), de índices e glossários (indicações marginais sobre as variantes das palavras), de tábuas explicativas, tudo isso complementando com excursos biográficos, questões gramaticais e até juízos de valor de natureza estética. 
O termo filologia é usado para designar o "[...] estudo global de um texto [...]" (Cambraia, 2005: 18), ou seja, a exploração exaustiva e conjunta de seus mais variados aspectos: linguístico, literário, crítico textual, sócio-histórico etc., contribuindo desta forma com o resgate, a recuperação e a transmissão do patrimônio cultural escrito de um povo, de uma língua, de uma determinada cultura.

O texto, assim, é a base para o estudo filológico. “[...] a Filologia concentra-se no texto, para explicá-lo, restituí-lo à sua genuidade e prepará-lo para ser publicado [...]." (Spina, 1997: 75). O estudo dos textos antigos tem importância também para outros pesquisadores e estudiosos de várias áreas de conhecimento, como a História, a Linguística, a Literatura, a Geografia e a Arqueologia, dentre outras.

Considerando que a transmissão de um texto sofre modificações ao longo do tempo, a Filologia tem "[...] como objetivo primordial [...] a restituição da forma genuína dos textos [...]." (Cambraia, 2005: 1), ou seja, procurar descobrir e explicitar qual foi a última vontade do autor. Para tanto, utilizam-se as técnicas da Paleografia, disciplina que trabalha com a análise dos caracteres gráficos, tipos de letras, sinais diacríticos, abreviaturas, uso de letras capitais, de iluminuras, de gravuras, para se entender a escrita do texto e atestar sua genuinidade.

Assim, esta atividade, que está vinculada aos projetos: "Para a História do Português Brasileiro - PHPB" - e "Estudo do português em manuscritos produzidos em Mato Grosso a partir do século XVIII" - MeEL/IL/ UFMT -, tem por objetivo o estudo filológico de uma carta manuscrita, pertencente ao Arquivo Público de Mato Grosso - APMT -, endereçada ao Governador e Capitão-general da Capitania de Mato Grosso, Luiz de Albuquerque de Mello Pereira e Cáceres, datada de 15 de fevereiro de 1784, escrita no Rio de Janeiro, com a realização das edições fac-similar e semidiplomática e a análise das funções adjetiva e transcendente da Filologia, além de características paleográficas, conforme Spina (1977: 76).

\section{EDIÇÕES FAC-SIMILAR E SEMIDIPLOMÁTICA}

Serão realizadas a seguir as edições fac-similar, reprodução fotomecânica, caracterizada por grau zero de intervenção do editor no manuscrito, e 
semidiplomática, que apresenta baixo grau de intervenção do editor no texto (Cambraia, 2005), marcada apenas pelo desdobramento das abreviaturas e, naturalmente, sua digitação, seguindo-se, com algumas adaptações, os critérios definidos por ocasião do II Seminário para a História do Português Brasileiro, realizado de 10 a 15 de maio de 1998, em Campos do Jordão, São Paulo. A opção pela edição semidiplomática se deve à preocupação de se procurar garantir a maior fidedignidade possível à forma original do manuscrito.

1. As linhas são enumeradas continuamente de cinco em cinco, uniformizando-se o texto à margem direita da mancha, ou à esquerda do editor.

2. As abreviaturas alfabéticas são desenvolvidas, registrando-se em itálico as letras nelas omitidas: Exemplos: Olle < $<\operatorname{Ill}^{\mathrm{mo}}$.> Illustrissimo (1r-1), ${ }^{3}$ $2 y_{x}^{2}<\mathrm{VEx}^{\mathrm{a}}$.> VossaExcellencia (1r-4).

3. A pontuação original é mantida.

4. A acentuação original, a presença ou ausência de diacríticos também são mantidos. Exemplos: hrea <hua> (1r-14), lemety <remetý> (1r-25), S-crex< < Goyáz> (1v-34).

5. As fronteiras de palavras são mantidas, assim como a grafia original. Exemplos: mofes <mefes> (1r-5) e ahowa <ahonra> (1r-5).

6. Não se introduz hífen ou qualquer outro sinal gráfico onde não há. Exemplos: Had <pa|ssada $>^{4}(1 \mathrm{r}-15 / 16)$.

7. O emprego de maiúsculas e minúsculas também é mantido como se apresenta no original.

8. A ortografia original é mantida, não se efetuando nenhuma correção ou atualização.

9. Os caracteres de leitura duvidosa são transcritos entre parênteses. Exemplo: $<\mathrm{p}(\mathrm{or})>(1 \mathrm{v}-50)$.

10. As intervenções de terceiros são indicadas entre colchetes [ ].

11. A assinatura é indicada entre diples $<>$.

3 Leia-se (1r-1) como fólio 1, recto, linha 1.

4 A barra vertical $(\mid)$, como em $<$ pa $\mid$ ssada $>$, indica mudança de linha no manuscrito. 
Carta-resposta ao Governador Capitão-general Luiz de Albuquerque de Mello Pereira...

\section{Fólio 1r}

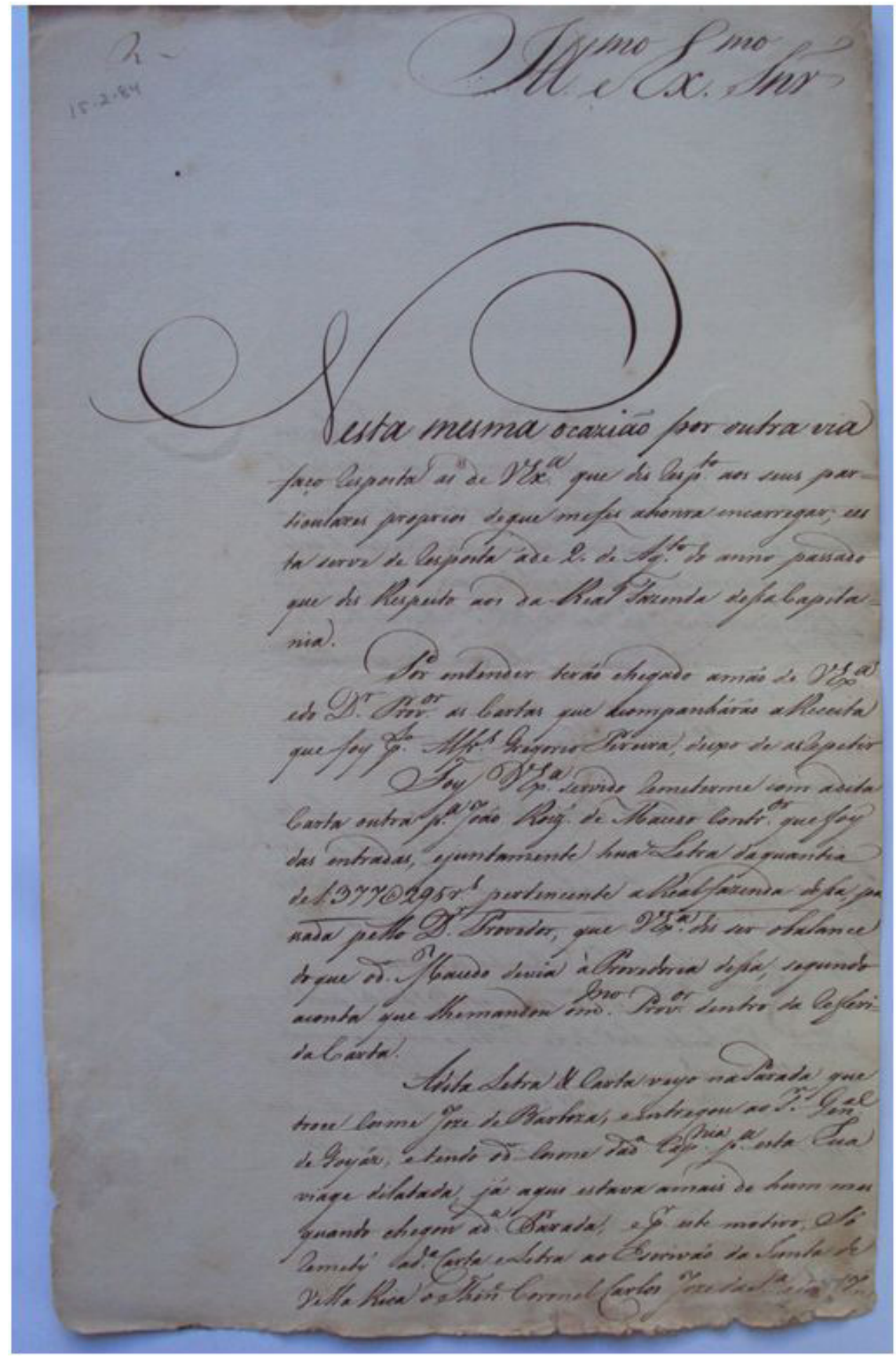


104 Camila Lemos de Almeida; Elias Alves de Andrade

\begin{tabular}{|l|l|}
\hline \multicolumn{2}{|l|}{ Edição semidiplomática } \\
\hline \multicolumn{2}{|l|}{ Transcrição - Fólio 1r } \\
\hline Código de identificação: BR APMT SEC CA 0918 Caixa 19 \\
\hline Assunto & $\begin{array}{l}\text { Carta de Manoel da Costa Cardoso ao Governador e Capitão-General da } \\
\text { Capitania de Mato Grosso Luis de Albuquerque de Mello Pereira e } \\
\text { Cáceres a respeito de cobrança de dívidas com o Erário Real. }\end{array}$ \\
\hline Local & Rio de Janeiro - RJ \\
\hline Data & 15 de Fevereiro de 1784. \\
\hline Assinatura & Idiógrafo \\
\hline
\end{tabular}

[Respondido] Illustrissimo eExcellentissimo Senhor

[15-2-84]

Nesta mesma ocaziaõ por outra via

faço resposta as" de VossaExcellencia que dis respeito aos seus par=

05 ticulares proprios de que mefes ahonra encarregar; ees

ta serve de resposta á de 2. de Agosto do anno passado

que dis Respeito aos daReal Fazenda dessaCapita=

nia.

Por entender terão chegado amão de VossaExcellencia

10 edo Doutor Provedor as Cartas que acompanhárão aReceita

quefoy pelo Alferes Gregorio Pereira, deixo de as repetir

Foy VossaExcellencia servido remeterme com adita

Carta outra para João Rodriguez de Macedo Contratador quefoy

das entradas, ejuntamente hua Letra da quantia

15 de1:377\$295 reis pertencente aRealfazenda dessa, pa

ssada pello Doutor Provedor, que VossaExcellencia dis ser obalance

do que odito Macedo devia áProvedoria dessa, segundo

aconta que lhemandou omesmo Provedor dentro da referi=

daCarta.

20 AditaLetra \& Carta veyo naParada que

troce Cosme Joze deBarboza, eentregou ao Senhor General

de Goyáz, etendoodito Cosme daditaCapitania para esta Sua

viage dilatada, já aqui estava amais de hum mês

quando chegou adita Parada, e por este motivo, Só

25 remetý aditaCarta eLetra ao Escrivão da Iunta de

VillaRica oThenenteCoronelCarlos JozedaSilva em 17, 
Carta-resposta ao Governador Capitão-general Luiz de Albuquerque de Mello Pereira...

\section{Fólio 1v}

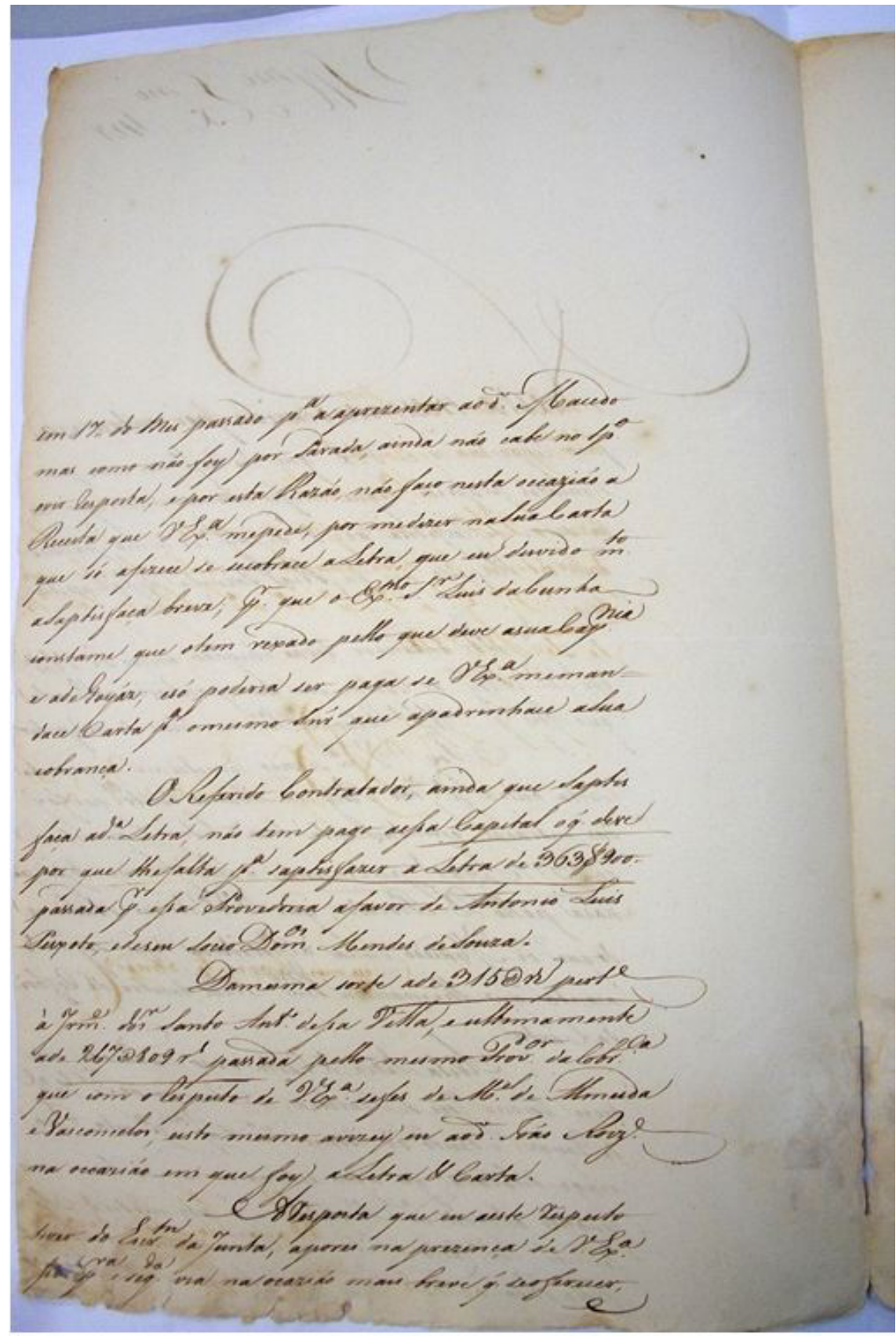


em 17,, do Mes passado para a aprezentar aodito Macedo mas como não foy por Parada, ainda não cabe no tempo ovir resposta, e por esta Razão, naõ faço nesta occazião a

30 Receita que VossaExcellencia mepede, por me dizer naSuaCarta que só afizece se secobrace aLetra, que eu duvido muito aSaptisfaça breve; por que oExcellentissimo Senhor Luis daCunha constame que otem vexado pello que deve asuaCapitania e adeGoyáz, esó poderia ser paga se VossaExcellencia meman=

35 dace Carta para omesmo Senhor que apadrinhace aSua cobrança.

O Referido Contratador, ainda que Saptis faça adita Letra, não tem pago aessa Capital o que deve por que lhefalta para saptisfazer aLetra de $363 \$ 900$.

40 passada por essa Provedoria afavor de Antonio Luis Peixoto, edeseu Socio Domingos Mendes deSouza.

Damesma sorte ade $315 \$$ reis pertencente á Jrmandade oSenhor Santo Antonio dessa Villa, eultimamente ade 267\$809 reis passada pello mesmo Provedor daCobrança

45 que com o respeito de VossaExcellencia sefes de Manoel de Almeida e Vasconcelos, eisto mesmo avizey eu aodito Ioão Rodriguez na occazião em que foy aLetra \& Carta.

A resposta que eu aeste respeito tiver doEscrivam da Junta, aporei na prezença deVossaExcellencia

$50 \mathrm{p}$ (or) $\mathrm{p}($ rov $)$ a e segunda via na ocazião mais breve que seoferecer, E 
Carta-resposta ao Governador Capitão-general Luiz de Albuquerque de Mello Pereira...

107

Fólio 2r

etalues pue ente mo Ythat por wa fe fourer.

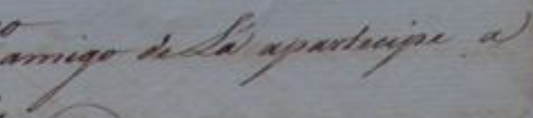
10

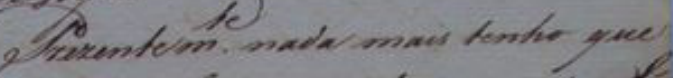

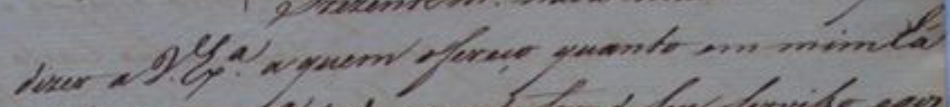

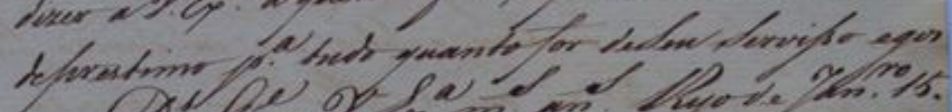

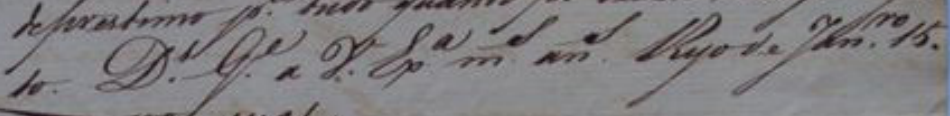
de terrofies gete.
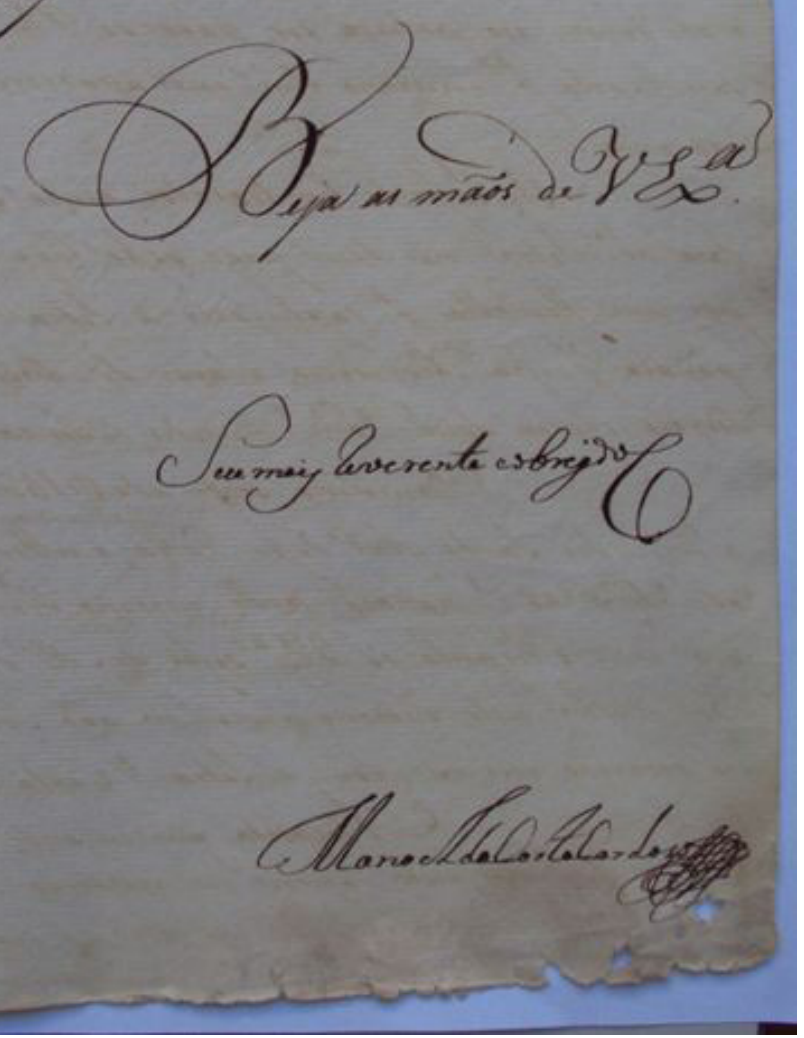

FLP 14 (1).indd 107

07/11/2012 15:04:29 
Fólio 2r

e talves que este mesmo amigo deLá apartecipe a

VossaExcellencia por via deGoyás.

Prezentemente nada mais tenho que

55 dizer a VossaExcellencia a quem ofereço quanto em mim há deprestimo para tudo quantofor deSeu Servisso egos

to. Deos Guarde a Vossa Excellencia muitos annos Ryode Janeiro 15.

de Fevereiro de1784..

Beja as mãos de VossaExcellencia

60 Seu mais reverente eobrigadoCriado

$<$ Manoel da Costa Cardoso $>$

\section{COMENTÁRIOS PALEOGRÁFICOS}

A Paleografia, de acordo com Spina (1977: 18), é o “[...] estudo das antigas escritas e evolução dos tipos caligráficos em documentos, isto é, em material perecível (papiro, pergaminho, papel)". Como disciplina auxiliar da Filologia, propicia análise e a descrição dos caracteres gráficos, tipos de letras, sinais diacríticos, abreviaturas, pontuação, acentuação, paragrafação, arabescos, dentre outros, possibilitando a leitura do texto e seu entendimento.

No manuscrito sob análise, a escrita utilizada foi a humanística ou italiana (Spina, 1977: 35), com letras cursivas, traçadas muitas vezes sem o descanso da mão. Tratando-se, provavelmente, de texto idiógrafo, ${ }^{5}$ é um documento produzido por mãos hábeis, ou seja, o escriba, copista ou amanuense, apresenta desenvoltura caligráfica, regularidade na escrita, com leve inclinação para a direita, uniformidade nas margens, sem borrões ou rasuras, dentre outras peculiaridades indicativas de boa instrução, como se pode verificar no excerto a seguir (1r-3 e 8):

5 Idiógrafo é o texto produzido por um escriba e assinado por um terceiro. 


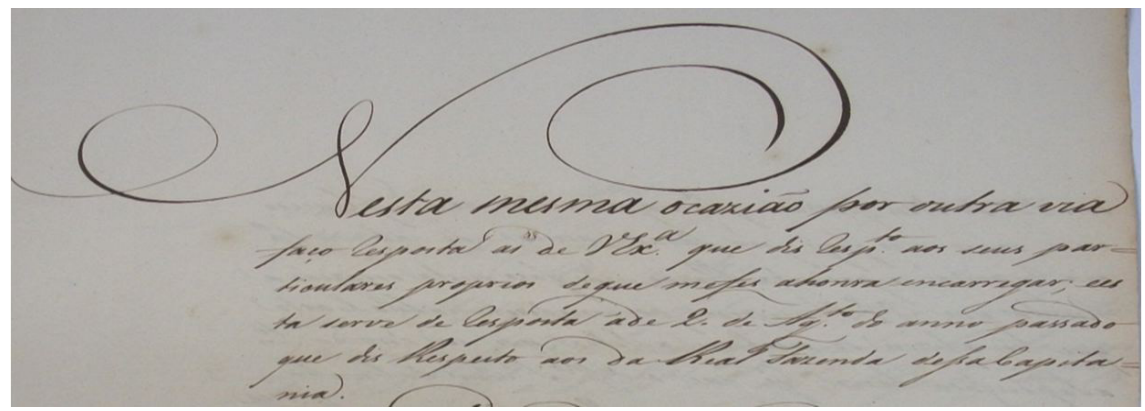

Nesta mesma ocaziaõ por outra via

faço resposta as" de VossaExcellencia que dis respeito aos seus par=

05 ticulares proprios de que mefes ahonra encarregar; ees

ta serve de resposta áde 2. de Agosto do anno passado

que dis Respeito aos daReal Fazenda dessaCapita=

nia.

Quanto às características ortográficas, no documento há ocorrência da letra ramista $<\mathrm{J}>$ por $<\mathrm{I}>$, assim chamada em razão do humanista francês, do século XVI, Petrus Ramus ou Pierre de La Ramée (1515-1572), que introduziu no alfabeto, além desta, o $<\mathrm{U}>$ por $<\mathrm{V}>$. Exemplos:

\begin{tabular}{|c|c|c|c|}
\hline$(1 \mathrm{r}-13)$ & $<$ João> & (2r-57) & $<$ Janeiro $>$ \\
\hline$(1 \mathrm{v}-46)$ & < Ioão> & $(1 r-25)$ & $<$ Iunta $>$ \\
\hline of oxe & $<$ Joze $>$ & $(1 \mathrm{v}-49)$ & $<$ Junta $>$ \\
\hline
\end{tabular}

Pode-se observar a existência de diversas realizações de grafia de uma mesma letra, em razão da coexistência de escritas de épocas diferentes, o que 
era um procedimento usual, ou de estilo pessoal de cada escriba, como se pode ver nos exemplos: $\quad<<\mathrm{d}>(1 \mathrm{r}-4), \quad d<\mathrm{d}>(1 \mathrm{r}-4), \quad \mathrm{SS}_{\mathrm{ss}}>(1 \mathrm{r}-6)$, $<\mathrm{ss}>(1 \mathrm{r}-7),<<>>(1 \mathrm{r}-20), \infty<\mathrm{P}>(1 \mathrm{r}-24), \quad<\mathrm{B}>(1 \mathrm{r}-21)$, $<\mathrm{B}>(2 \mathrm{r}-59), \quad<\mathrm{r}>(1 \mathrm{v}-48),<\mathrm{r}>(1 \mathrm{v}-29), f_{l}<\mathrm{R}>(1 \mathrm{v}-29)$, $<\mathrm{R}>(1 \mathrm{v}-46)$.

As abreviaturas que, conforme Spina (1977: 44-49), são classificadas por sigla, síncope, apócope, com letras sobrepostas, numerais, com letras sobrepostas, e signos especiais são encontradas no manuscrito, como se pode ver em: abreviaturas, por sigla: $0<<$ Vossa $>$ (2r-57), e por síncope, com letras sobrepostas: Ullime $<$ Illustrissimo $>(1 \mathrm{r}-1)$, $=<$ Agosto $>(1 \mathrm{r}-6)$, D. Frov $<$ Doutor Provedor > (1r-10), lno <omesmo $>$ (1r-18), $<$ Silva $>(1 \mathrm{r}-26) \mathrm{e} \longrightarrow$ ter $^{2}<$ Fevereiro $>$ (2r-58).

São registradas no corpus ocorrências dos seguintes diacríticos:

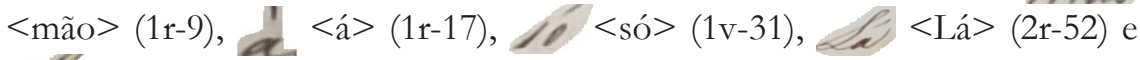
L) <há> (2r-55).

Há também no manuscrito a presença de traços de oralidade, como em:

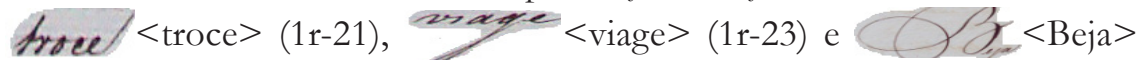
(2r-59).

Além disso, são detectadas algumas ocorrências de poligrafia, como em:

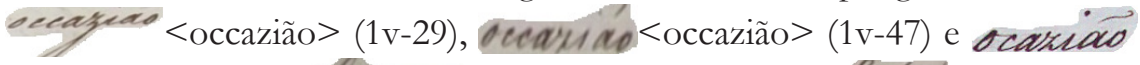
$<$ ocaziaõ $>$ (1r-3), Csorivae $<$ Escrivão $>(1 \mathrm{r}-25)$, Line $<$ Escrivam $>$ (1v-49), dado que, à época, não havia uniformidade nos procedimentos de escrita, o que veio a acontecer apenas em 1904, com Ortografia Nacional, de Gonçalves Viana.

No que se refere à pontuação, emprega-se a vírgula, como nos excertos:
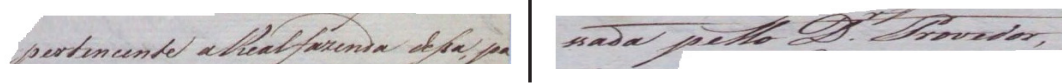

[...] pertencente aRealfazenda dessa, pa $\mid$ ssada pelo Doutor Provedor [...]. (1r-15 e 16)

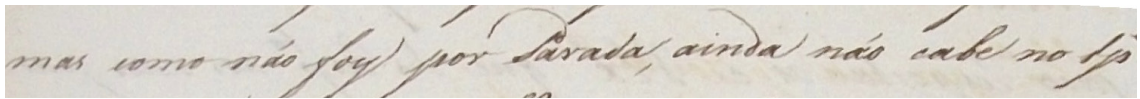

[...] mas como não foy por Parada, ainda não cabe no tempo [...]. (1v-28) 
Carta-resposta ao Governador Capitão-general Luiz de Albuquerque de Mello Pereira...

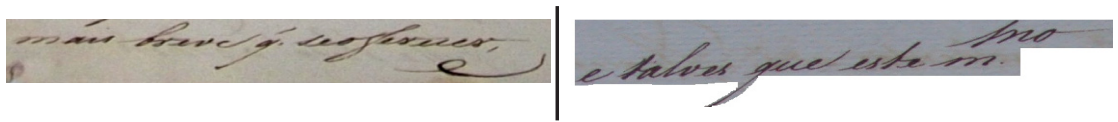

[...] mais breve que seoferecer, |e || e talves que este mesmo [...] (1 v-50 e 51 e 2 r- -1$){ }^{6}$

O ponto e vírgula é encontrado em:

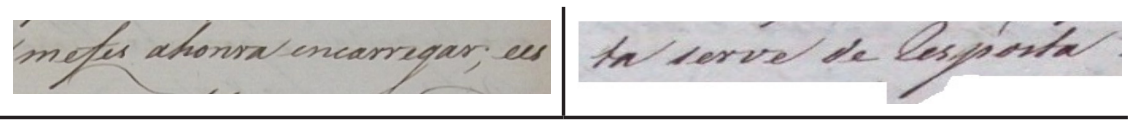

[...] mefes ahonra encarregar; ees | ta serve de resposta [...] (1r -5 e 6)

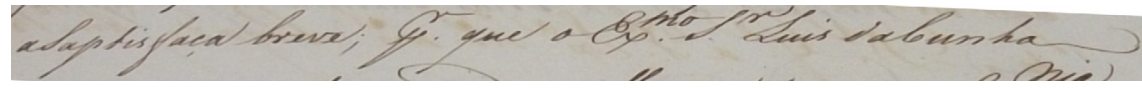

[...] aSapstifaça breve; por que oExcellentissimo Senhor Luis daCunha [...] (1v -32).

O ponto é usado, na maioria das vezes, no final de parágrafo, como nos exemplos:

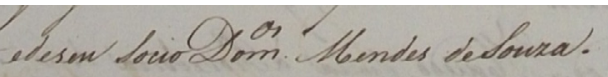

[...] edeseu Socio Domingos Mendes deSouza. (1v-41)

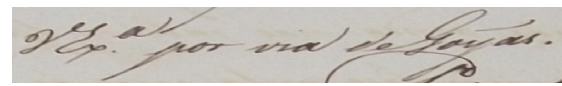

[...] VossaExcellencia por via deGoyás. (2r-53).

Os dois pontos são utilizados em referência numérica, em elementos não alfabéticos, como em:

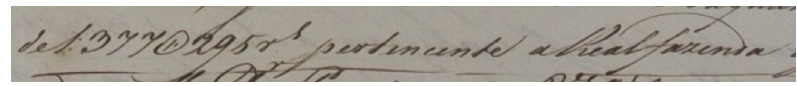

[...] de1:377\$295 reis pertencente aRealfazenda [...] (1 $\mathrm{r}-15)$

6 A barra dupla vertical ( II ) é empregada para indicar mudança de fólio. 
Há ocorrências de separação vocabular translinear com hífen duplo $(=)$ e sem hífen, como em: s par Lioulares <par=| ticulares $>(1 \mathrm{r}-4 \mathrm{e} 5)$, Gapita $\mid$ nia). $<$ Capita $=\mid$ nia $>(1 \mathrm{r}-7$ e8) eer $\mid$ the $-<$ ees $\mid$ ta $>(1 \mathrm{r}-5$

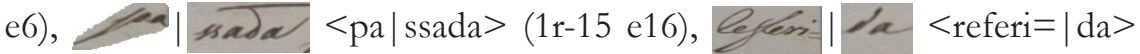
(1r-18 e19) e meman $\Rightarrow \mid$ dacel $<$ meman $=\mid$ dace $>$ (1v-34 e36), não se registrando casos de separação vocabular intralinear.

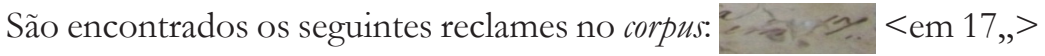
(1r-25), que se repete em (1v-27) e $e<\mathrm{e}>(1 \mathrm{v}-51)$.

Por fim, observa-se ocorrência de cetras, ao final da assinatura, recurso que lhe imprime característica pessoal, procurando dificultar ou evitar sua falsificação: (2r-61).

\section{AS FUNÇÕES ADJETIVAE TRANSCENDENTE DA FILOLOGIA NO MANUSCRITO}

O texto é condição para a existência da Filologia que, segundo Spina (1977: 77), possui três funções: substantiva, adjetiva e transcendente. Dentre os objetivos deste artigo, está o estudo do manuscrito sob o ponto de vista das funções adjetiva e transcendente, entendendo-se por adjetiva aquela que não se fixa propriamente no texto, mas dele extrai informações como características de seu autor ou do local onde foi escrito, e, por transcendente, aquela que, também não se atendo ao texto, tem-no apenas como fonte para o estudo de aspectos que estão fora dele, como questões relativas à história social nele apenas sugeridas.

A propósito da função adjetiva da Filologia, pode-se deduzir do manuscrito, uma carta, que, embora não esteja explicitado o nome para quem é enviada, infere-se, pelo tratamento formal da linguagem utilizada, tratar-se de carta em resposta ao quarto Governador e Capitão-general da Capitania de Mato Grosso, Luiz de Albuquerque de Melo Pereira e Cáceres, que, nomeado por Carta Régia de 03 de julho de 1771, tomou posse em 13 de dezembro de 1772, tendo permanecido no cargo por 17 anos.

A respeito deste governador, Siqueira (2002: 53) afirma:

Um capitão-general assumiu destaque na fortificação e expansão da fronteira Oeste: foi o $4^{\circ}$ capitão-general, Luís de Albuquerque de Melo 
Pereira e Cáceres, fidalgo lusitano, militar de carreira, assessorado por cientistas e engenheiros responsáveis pelos trabalhos militares e científicos desenvolvidos em terras mato-grossenses[...].

A seguir, encontram-se excertos do manuscrito referindo-se a Luiz de Albuquerque de Melo Pereira e Cáceres.

\begin{tabular}{|c|c|}
\hline & $<$ VossaExcellencia $>(1 \mathrm{r}-4)$ \\
\hline & $<$ Beja as mãos de VossaExcellencia > (2r-59) \\
\hline & $\begin{array}{l}<\text { Deos Guarde a Vossa Excellencia muitos annos } \\
\text { Ryode Janeiro 15. de Fevereiro de1784.. }>\text { (2r- } \\
\qquad 57 \text { e 58) }\end{array}$ \\
\hline
\end{tabular}

Quanto ao missivista da carta, Manoel da Costa Cardoso, cuja assinatura se pode ver a seguir, residiu no Rio de Janeiro, onde foi um dos negociantes mais prósperos, tendo tido grande influência e autoridade junto à administração da Real Fazenda no Brasil, quando reinava em Portugal D. Maria I, período em que foi redigida a carta em análise.

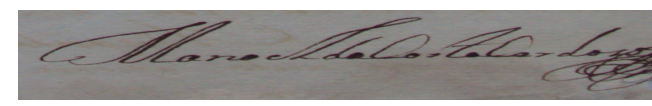

$<$ Manoel da Costa Cardoso $>$ $(2 r-61)$

Já pela função transcendente da Filologia, pode-se perceber pelo manuscrito os aspectos político-administrativos que compunham o cenário ao tempo em que foi produzido, de dependência do Brasil colonial, que praticamente mantinha, com ouro e produtos primários, a Coroa portuguesa. Tendo, obrigatoriamente, que prestar contas da arrecadação de impostos ao Real Erário, as Juntas da Real Fazenda no Brasil colônia usavam, como instrumentos, os sistemas de administração contábil-fazendária implementados pelo Primeiro-Ministro português, Sebastião José de Carvalho e Melo, o Marquês de Pombal, durante o reinado de D. José I. 
Tal dependência, na prática, consubstanciava-se na instituição do Vice-Reinado, cuja capital era o Rio de Janeiro, cuja autoridade máxima era o Vice-Rei, D. Luiz de Vasconcelos, e, na Capitania de Mato Grosso, o governador Capitão-general, Luiz de Albuquerque de Mello Pereira e Cáceres, fidalgo português de confiança da Coroa, a quem foi conferida a responsabilidade de guarda e manutenção da região fronteiriça da Colônia. O excerto a seguir ilustra as relações que houve, à época, entre as duas autoridades.

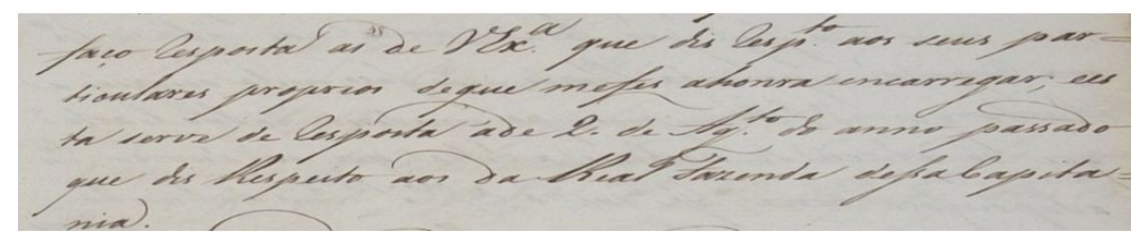

[...] faço resposta as" de VossaExcellencia que dis respeito aos seus par=

05 ticulares proprios de que mefes ahonra encarregar; ees ta serve de resposta áde 2. de Agosto do anno passado que dis Respeito aos daReal Fazenda dessaCapita $=$ nia. (1r-4 a 8$)$

As Juntas da Real Fazenda mantinham rigidamente o controle da Colônia brasileira, ao exercer as funções de controlar as despesas e a arrecadação de tributos, dentre os quais a entrada de mercadorias, um dos grandes “[...] tributos coloniais, bem como os dízimos, subsídio literário e décima predial e uma série de processos de confiscos reais [...]." (Carrara, 2003: 28).

No excerto a seguir, João Rodrigues de Macedo, que era contratador de tributos e uma mistura de banqueiro, negociante e coletor de impostos, foi mencionado como devedor à Provedoria da Real Fazenda, em relato de Manoel da Costa Cardoso ao Governador Capitão-general da Capitania de Mato Grosso. 


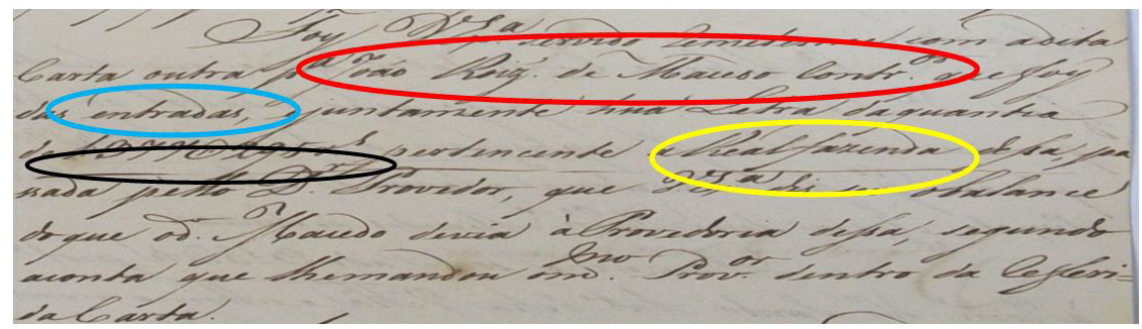

$<$ Foy VossaExcellencia servido remeterme com adita Carta outra para João Rodriguez de Macedo Contratador quefoy das entradas, ejuntamente hua Letra da quantia de1:377\$295 reis pertencente aRealfazenda dessa, pa ssada pello Doutor Provedor, que VossaExcellencia dis ser obalance do que odito Macedo devia áProvedoria dessa, segundo aconta que lhemandou omesmo Provedor dentro da referi= daCarta.> (1r-12 a 19)

A cobrança de impostos, uma dentre as muitas responsabilidades das autoridades citadas, se dava em locais específicos como a Casa dos Contos, cuja fotografia pode ser vista a seguir, construída em Vila Rica, Capitania de Minas Gerais, entre 1782 e 1784, para residência de João Rodrigues de Macedo, como benevolência Real, concessão feita pela Coroa a autoridades e nobres nas colônias portuguesas, responsáveis pela recolha de tributos.

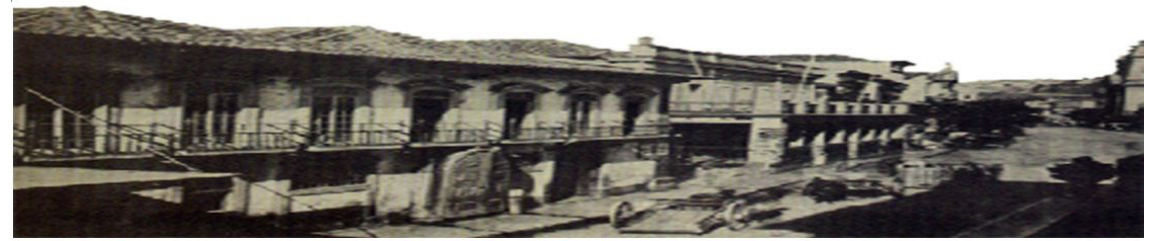

Fonte: Adaptação da imagem disponível em: <http://200anos.fazenda.gov.br/linha-do-tempo/1800-1899>. Acesso em: 15 de maio de 2010.

A Casa dos Contos, serviu, durante a Inconfidência Mineira, além de local para aquartelamento das tropas do Vice-Rei, também de prisão para conjurados como o cônego de Mariana, Luís Vieira da Silva, e Cláudio Manuel da Costa. 
Mais tarde, João Rodrigues de Macedo, em razão de muitas dívidas com a Fazenda Real, teve seus bens confiscados, inclusive a Casa dos Contos, definitivamente incorporada à Coroa em 1803. Em 1792, as atividades de cobrança de tributos foram transferidas para a sede da administração e contabilidade pública da Capitania de Minas Gerais, em Vila Rica, atual Ouro Preto.

Outro credor citado na referida carta é Luís da Cunha Menezes, ${ }^{7}$ Governador Capitão-general da Capitania de Minas Gerais (1783-1788), “[...] tristemente célebre pelos seus desmandos [...]” (Holanda, 1982: 396), cujo nome é mencionado no excerto seguinte:

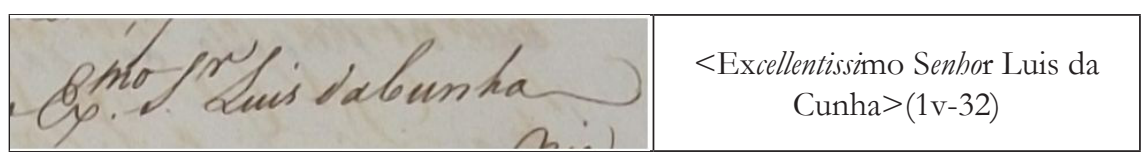

A cobrança de impostos, que se fazia em ouro através do 'quinto' e, após, da 'capitação', ${ }^{8}$ também foi feita em moedas que circularam no período colonial brasileiro, cunhadas em prata, nos valores de 600, 300, 150 e 75 réis. Entretanto, para facilitar o comércio na região das minas, os preços eram estabelecidos em função do preço do ouro, sendo 1.200 réis para cada 3,586 gramas de ouro. Essas moedas foram gravadas com série "J", iniciais do nome de D. José I, visando diferenciá-las das patacas, moedas de prata, que circularam por mais tempo na Colônia, de 1695 a 1834, nos valores de 20, 40, 80, 160, 320 e 640 réis.

Sobre o sistema monetário da época, Holanda (1982: 351) afirma:

Outra consequência nociva ao Brasil foi que nosso sistema monetário era verdadeiramente anárquico, até a ocasião da vinda da Família Real Portuguêsa. Havia várias relações legais entre o ouro e a prata [...]. A co-

7 Luís da Cunha de Menezes inspirou o poeta Tomás Antônio Gonzaga a escrever as Cartas Chilenas, chamando-o de Fanfarrão Minésio.

8 O 'quinto' correspondia à quinta parte do que fosse extraído de ouro nas minas que, substituído pela 'capitação', visava ao aumento da arrecadação de tributos, "[...] imposto cobrado dos mineradores por cabeça de escravo, produtivo ou não, homem ou mulher, maiores de doze anos." (Andrade: 2007: 39). 
existência de três moedas, de mesmo valor nominal e diferentes valôres reais, provocava multiplicidade de preços e favorecia especulações [...].

No reinado de D. Maria I, as moedas de ouro registraram diferentes momentos da vida de D. José I, retratado nelas após sua morte. Entretanto, de 1777 a 1786, a própria rainha foi nelas retratada, ao lado de seu marido, D. Pedro III, depois de cuja morte aparece sozinha, portando véu de viúva. Terminado o luto, a partir de 1789, passou a ser representada nelas com um toucado ornado de joias e fitas. A seguir, as moedas e a gravura de D. Maria I:
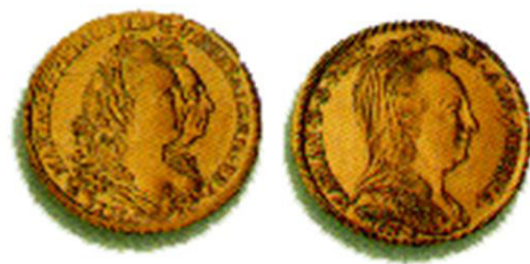

D. Maria I ao lado de D. Pedro III
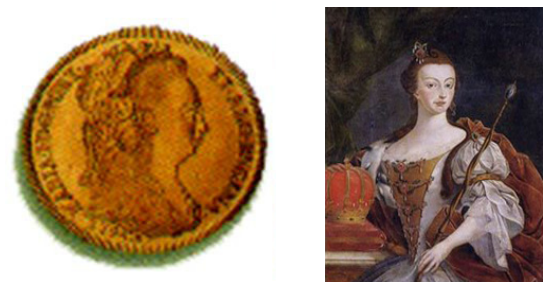

Após a viuvez Gravura de D. Maria I

Ao final do século XVIII, em face da crise do sistema colonial português, da independência dos Estados Unidos da América e da Revolução Francesa, as ideias libertárias no Brasil colonial estavam em efervescência. Assim, o interesse por informações sobre a real situação econômica da Capitania de Mato Grosso, revelado nesta carta manuscrita em resposta a correspondência de Luiz de Albuquerque de Melo Pereira e Cáceres, era plenamente justificável, dado o cenário que já se vislumbrava na relação comercial metrópole-colônia, uma vez que "[...] o Brasil português começou a receber o impacto de grandes transformações que ocorriam no cenário internacional [...].” (Linhares, 2000: 122).

\section{CONSIDERAÇÕES FINAIS}

As análises feitas neste artigo correspondem a estudos ainda preliminares de um projeto de dissertação de mestrado em andamento sobre manuscritos referentes à Capitania de Mato Grosso, que naturalmente fez parte do sistema 
contábil-fazendário do Brasil colonial, subordinado à Coroa portuguesa, assim como as Capitanias de Minas Gerais e Goiás, citadas na carta manuscrita em análise, obrigadas a prestar contas ao Erário Real, em conformidade com as medidas administrativas iluministas impostas pelo Marquês de Pombal.

A recuperação de documentos antigos, com a edição semidiplomática de manuscritos, possibilita o acesso a informações históricas de inquestionável valor para os interessados em estudar, além de características filológicas e paleográficas, aspectos socioeconômicos, culturais e históricos de uma determinada região e de um povo, por meio das funções adjetiva e transcendente da filologia, conforme se procurou fazer neste artigo.

\section{BIBLIOGRAFIA}

ACIOLI, V. L. C. 2003. A escrita no Brasil Colônia: Um guia para a leitura de documentos manuscritos. Recife: Fundação Joaquim Nabuco; Editora Massangana.

AMATO, C.; NEVES, I. S.; RUSSO, A. 2004. Livro das moedas do Brasil: 1643 até o presente. 11. ed. São Paulo: C. AMATO.

ANDRADE, E. A.; BARONAS, R. L.; SANTIAGO-ALMEIDA, M. M. 2012. Plano de guerra da Capitania de Matto Grosso - Janeiro de 1800. Cuiabá: EdUFMT.

. 2010. Cotejo de manuscritos do século XIX. In: Revista Caligrama. Belo Horizonte: UFMG, ISSN 0103-2178,V. 15, N. 2, <www.letras.ufmg/caligrama>, p. 161-187.

. 2008/2009. Aspectos da sintaxe em manuscritos modernos. In: Revista Filologia e Lingüística Portuguesa. São Paulo: FFLCH/USP, n. 10/11, ISSN 2176-9419, p. 149-172.

AZEVEDO FILHO, L. A. 1987. Iniciação em crítica textual. São Paulo: EdUSP.

BRASIL, Ministério da Fazenda. Portal MF 200 anos. Disponível em: <http://200anos. fazenda.gov.br/linha-do-tempo/1800-1899>. Acesso em 15 de maio de 2010.

CAMBRAIA, C. N. 2005. Introdução à crítica textual. São Paulo: Martins Fontes.

CARrARA, A. A. 2003. A Real Fazenda de Minas Gerais: guia de pesquisa da coleção Casa dos Contos de Ouro Preto. Ouro Preto: UFOP. V. 1.

CARVALHO, J. L. Retrato de D. Maria I. Imagem disponível em: < http://pt.wikipedia. org/wiki/Ficheiro:Jcarvalho-dmariaI-mhn.jpg >. Acesso em 10/08/2011.

COSTA, F D. 1992. Capitalistas e serviços: Empréstimos, contratos e mercês no final do século XVIII. Análise Social. XXII(116-117), p. 441-460.

FLEXOR, Maria. H. O. 2008. Abreviaturas: Manuscritos do século XVI ao XIX. 3. ed revisada e aumentada. Rio de Janeiro: Arquivo Nacional. 
FREYRE, G. 1978. Contribuição para uma sociologia da Biografia: o exemplo de Luiz de Albuquerque governador de Mato Grosso no fim do século XVIII. Cuiabá: Fundação Cultural de Mato Grosso.

HOLANDA, S. B. 1982. História geral da civilização brasileira. A época colonial: administração, economia, sociedade. 5. ed. Vol. 2. Tomo I. São Paulo: DIFEL.

HIGOUNET, C. 2003. História concisa da escrita. 13.ed. corrigida. São Paulo: Parábola Editorial.

JESUS, N. M. 2008. Disfarces e cautelas: o governo de Luis de Albuquerque de Mello Pereira e Cáceres e o contrabando na fronteira oeste da América Portuguesa. In: Revista Humanidades. UFRN. V. 9 n. 24, set./out., p.1-11.

LINHARES, M. Y. (Org.). 2000. História geral do Brasil. 9. ed. Rio de Janeiro: Campus.

LOBO, R. H. 1968. História Universal. V. I. São Paulo: Melhoramentos.

PIRENNE, J. 1973. Panorama da História Universal. (Tradução de Octavio Mendes Cajado). São Paulo: EdUSP.

SANTIAGO-ALMEIDA, M. M. 2000. Aspectos fonológicos do português falado na baixada cuiabana: Traços de língua antiga preservados no Brasil (Manuscritos da época das Bandeiras, século XV III). Tese (Doutorado), Faculdade de Filosofia, Letras e Ciências Humanas, Universidade de São Paulo.

SILVA, P. C. P. S. 1993. Governantes de Mato Grosso. Cuiabá: Arquivo Público do Estado de Mato Grosso.

SIQUEIRA, E. M. 2002. História de Mato Grosso: da ancestralidade aos dias atuais. Cuiabá: Entrelinhas.

SPAGGIARI, B.; PERUGI, M. 2004. Fundamentos da Crítica Textual. São Paulo: Lucerna. SPINA, S. 1997. Introducão à Edótica: crítica textual. São Paulo: Cultrix.

TONIAZZO, C. L. 2011. Lembranças de Mato Grosso sob um olhar feminino: um estudo filológico. Dissertação (Mestrado), Instituto de Linguagens, Universidade Federal de Mato Grosso. Cuiabá: UFMT.

TOVAR, A. 1944. Linguística y Filologia Clasica: su situación actual. Madrid: Revista de Occidente. 
120 Camila Lemos de Almeida; Elias Alves de Andrade

\title{
Letter in reply to the Governor General Captain Luiz de Albuquerque de Mello Pereira e Cáceres: A Philological Study
}

\begin{abstract}
This article is a philological study of a manuscript dated 15 January 1784, written in Rio de Janeiro, and part of the Public Archive of the state of Mato Grosso, Brazil, from which facsimile and semi-diplomatic editions are produced and paleographic aspects analyzed, with an examination of characteristics relative to the adjectival and transcendental functions of Philology, as defined in Spina (1977: 77). This activity is linked to the projects "Towards the History of Brazilian Portuguese" ("Para a História do Português Brasileiro - PHPB") - and "A Study of Portuguese in manuscripts produced in Mato Grosso from the 18th Century onwards" ("Estudo do português em manuscritos produzidos em Mato Grosso a partir do século XVIII"), within the Post-Graduate Language Studies Program at the Language Institute of the Federal University of Mato Grosso, Brazil.
\end{abstract}

Keywords: Adjectival and Transcendent Functions; Edition; Manuscript; Paleography; Philology.

Recebido em: 15/11/2011

Aprovado em: 09/04/2012 